\title{
Asymptomatic ischaemia during daily life in stable coronary disease: relevant or redundant?
}

\author{
David Mulcahy, Henry Purcell, Deven Patel, Kim Fox
}

Asymptomatic ischaemia during daily life has been a controversial topic for 20 years since the first report detailing episodes of silent ST segment depression during sleep in patients with coronary disease. ${ }^{1}$ Asymptomatic ischaemic episodes are now known to be common during daily life in such patients. ${ }^{2}$ Though there are various theories why some episodes of ischaemia are asymptomatic and others symptomatic, ${ }^{3-5}$ both types of episode have similar underlying characteristics ${ }^{67}$ and haemodynamic consequences. ${ }^{89}$

Asymptomatic ischaemic episodes during daily life are viewed as being bad for the patient with coronary disease, and therefore their detection and eradication are believed to be beneficial. The need to seek and treat will depend on showing that asymptomatic ischaemia during daily activities is associated with an adverse prognosis and, more importantly, on showing that such treatment improves outcome.

In the past five years there have been nine long-term ( $>1$ year follow up) prognostic studies of ambulatory ST segment monitoring in over 1000 patients with stable coronary disease who either had known coronary disease or who were being treated for angina. We have reviewed these studies in an attempt to assess the prognostic significance of asymptomatic ischaemia during daily life for the subsequent hard end points of acute myocardial infarction and cardiac death and to soft end points of unstable angina and requirement for revascularisation.

\section{Studies of stable angina}

Rocco and colleagues reported in 1988 on the outcome at 12.5 months of 86 medically treated patients with stable angina with positive exercise tests who had undergone ambulatory ST segment monitoring. ${ }^{10}$ Forty nine patients $(57 \%)$ had ischaemic episodes $(86 \%$ asymptomatic) during daily activities, and all but one of the 15 patients $(17 \cdot 4 \%)$ who had one or more cardiac event over the follow up period had ischaemic episodes. All six recorded "hard" events (myocardial infarction $(n=4)$ and cardiac death $(n=2))$ occurred in this subgroup.

Deedwania and Carbajal reported on 107 medically treated patients with stable angina who had a positive exercise test and who underwent ST segment monitoring. ${ }^{11}$ Forty six (43\%) patients had ischaemic episodes during daily life (87\% asymptomatic). During the 23 month follow up 16 cardiac deaths were recorded-11 in the 46 patients with ambulatory ischaemia. A further 36 patients had non-fatal events; 15 of these occurred in the subgroup with ambulatory ischaemia. Thus over a 23 month period $50 \%$ of the study population had cardiac events: these included a $25 \%$ mortality in those with episodes of ischaemia during daily activities.

Tzivoni et al reported on the outcome at 23 months in 56 patients with stable angina who had ambulatory ST segment monitoring. ${ }^{12}$ All had a positive exercise test and confirmed coronary disease. Of the $43(77 \%)$ patients who had ischaemia during monitoring, 31 $(72 \%)$ had a cardiac event (death, $n=6$; myocardial infarction, $n=6$; coronary artery bypass grafting (CABG), $n=14$; percutaneous transluminal coronary angioplasty (PTCA), $n=2$; unstable angina, $n=3$ ) compared with three of 13 patients without ischaemia (unstable angina $\mathrm{n}=2$; PTCA, $n=1)$. The overall event rate in this selected group of treated patients with stable angina was $61 \%$ at less than two years.

The above reports ${ }^{10-12}$ of 249 patients suggest that the presence of asymptomatic ischaemia is detrimental. It is surprising, however, that such high event rates were recorded over short follow up periods in "stable angina patients on therapy", even allowing for the selection of the patients, when it is known that the overall outlook for patients with stable angina is good. ${ }^{13}$

In 1991 Yeung et al, ${ }^{14}$ in a follow-up report on the original cohort of patients described by Rocco et al ${ }^{10}$ and on a further 52 patients (all with a positive exercise test), noted that the prognostic significance of episodes of ischaemia during daily life for subsequent acute myocardial infarction and cardiac death was lost after 2 years, though such changes continued to identify those more likely to have any cardiac event (including unstable angina and revascularisation) for up to five years. During the mean 37 month follow up period a total of 39 patients $(30 \%)$ had at least one cardiac event (mainly CABG). Nine patients with ambulatory ischaemia died or had myocardial infarction compared with four patients without such changes.

Mulcahy et al reported on the two year outcome of 172 patients with symptoms of stable angina on therapy who underwent 48 hour ambulatory ST segment monitoring and exercise testing. ${ }^{15}$ Unlike previous studies, a positive exercise test was not a prerequisite 
for inclusion. One hundred and four patients $(60.5 \%)$ had a positive exercise test and 72 $(42 \%)$ had ischaemia during daily activities. Twenty five patients (15\%) had cardiac events during follow up (non-fatal myocardial infarction, $\mathrm{n}=6(3.5 \%)$; cardiac death, $\mathrm{n}=3$ $(1 \cdot 7 \%)$; unstable angina, $n=6 ; \mathrm{CABG} /$ PTCA, $n=10$ ). Only one non-fatal infarction and one cardiac death occurred in those with ischaemic episodes during daily life. Of the soft end points recorded, two of six with unstable angina and six of 10 requiring revascularisation had episodes of ischaemia during ambulatory monitoring.

Quyyumi et al reported on 116 "low-risk" patients with stable (and confirmed) coronary artery disease who underwent ambulatory ST segment monitoring and exercise testing. ${ }^{16}$ They excluded patients with left main disease, three vessel disease with left ventricular dysfunction, three vessel disease with inducible ischaemia, and two vessel disease with left ventricular dysfunction and inducible ischaemia, because such patients would tend to be referred routinely for intervention on present practice. Of their study group $72(63 \%)$ patients had a positive exercise test for ischaemia and 45 (39\%) had ischaemia ( $82 \%$ episodes asymptomatic) during daily activities. Over the 29 month follow up no deaths and seven myocardial infarctions (6\%) were recorded; only one infarction occurred in a patient with ambulatory ischaemia. A further 10 patients had subjective events (unstable angina, $n=1$; revascularisation, $n=9$ ): five occurring in those with ambulatory ischaemia. The total event rate over 29 months follow up was therefore $15 \%$ in treated patients with stable angina, similar to that reported by Mulcahy et al (table 1).

In the last three published studies ${ }^{14-16}$ of 426 patients with stable angina, the presence of predominantly asymptomatic ischaemia during daily life did not identify patients who were more likely to have a subsequent acute myocardial infarction or cardiac death during follow up $(24 \cdot 5-37$ months). In those studies for which a positive exercise test was not a prerequisite for inclusion, ${ }^{1516} 11$ of 102 patients without ischaemia during either exercise testing or ambulatory monitoring had acute cardiac events compared with four of 107 patients with evidence of ischaemia during both investigations.

\section{Studies after infarction and revascularisation}

There have been three studies of the prognostic significance (follow up 24-48 months) of mainly asymptomatic ischaemia detected in the stable phase after either acute myocardial infarction $^{1718}$ or coronary artery bypass surgery. ${ }^{19}$ Studies that incorporated monitoring before hospital discharge were not considered. Tzivoni et al studied 224 patients who underwent ambulatory ST segment monitoring at a mean of two years after acute myocardial infarction. ${ }^{17}$ One hundred and seventeen patients $(52 \%)$ had a positive exercise test and 74 (33\%) had ischaemic episodes during daily life (all 74 also had a positive exercise test). A total of 56 events was reported over the 28.5 month follow up. The presence of ischaemic episodes during daily life did not help identify those more likely to have subsequent reinfarction or cardiac death.

Solimene et al performed ambulatory ST segment monitoring in 40 patients eight weeks after a first myocardial infarction and followed them for two years. ${ }^{18} \mathrm{Six}$ patients had asymptomatic ischaemia during ambulatory monitoring. No events occurred in them: there was one cardiac death, in a patient without ischaemia. Kennedy et al performed ambulatory ST segment monitoring on 220 patients in the stable phase after coronary artery bypass surgery and followed them for 48 months. ${ }^{19}$ Silent ischaemic episodes were detected in up to $30 \%$ of patients $(99 \%$ asymptomatic). None of the eight patients who experienced acute myocardial infarction or cardiac death and only three of eight

Table 1 Studies (published between 1988-1993) to assess the prognostic significance of transient ischaemia during daily life in patients with stable coronary artery disease. The patients reported by Rocco et al (1988) are detailed in a larger publication with longer follow up by Yeung et al in 1991. Only 171 patients studied late after CABG by Kennedy et al are cited in the analysis of events. Selected = patients only studied if they had confirmed ischaemia during exercise testing. (Unselected = positive exercise test not a prerequisite for inclusion. All events = myocardial infarction, cardiac death, unstable angina, $C A B G / P T C A)$.

\begin{tabular}{|c|c|c|c|c|c|c|c|c|c|c|}
\hline Study & $\begin{array}{l}\text { Patients } \\
\text { (n) }\end{array}$ & $\begin{array}{l}\text { Follow up } \\
\text { (mnth) }\end{array}$ & $\begin{array}{l}\text { Positive } \\
\text { exercise } \\
\text { test }\end{array}$ & $\begin{array}{l}\text { Positive } \\
\text { tapes }\end{array}$ & $\begin{array}{l}\text { Hard } \\
\text { events, } \\
\text { positive } \\
\text { tapes }\end{array}$ & $\begin{array}{l}\text { Total } \\
\text { events, } \\
\text { positive } \\
\text { tapes }\end{array}$ & $\begin{array}{l}\text { Hard } \\
\text { events, } \\
\text { negative } \\
\text { tapes }\end{array}$ & $\begin{array}{l}\text { Total } \\
\text { events, } \\
\text { negative } \\
\text { tapes }\end{array}$ & $\begin{array}{l}\text { All events } \\
\text { combined }\end{array}$ & $\begin{array}{l}\text { Significance } \\
\text { of ambulatory } \\
\text { ischaemia for } \\
\text { hard events }\end{array}$ \\
\hline $\begin{array}{l}\text { Selected patients: } \\
\text { Tzivoni et al } \\
\text { (1989) }\end{array}$ & 56 & 23 & $100 \%$ & (43) $77 \%$ & (12) $28 \%$ & (31) $72 \%$ & (0) $0 \%$ & (3) $23 \%$ & (34) $60 \%$ & Yes \\
\hline $\begin{array}{l}\text { (1990) } \\
\text { Yeung et al (1991) }\end{array}$ & $\begin{array}{l}107 \\
138\end{array}$ & $\begin{array}{l}23 \\
37\end{array}$ & $\begin{array}{l}100 \% \\
100 \%\end{array}$ & (46) $43 \%$ & $\begin{array}{l}\text { (12) } 26 \% \\
(9)-\end{array}$ & $\begin{array}{l}\text { (26) } 56 \% \\
(25)-\end{array}$ & $\begin{array}{l}\text { (6) } 9 \cdot 8 \% \\
(4)-\end{array}$ & $\begin{array}{l}\text { (26) } 43 \% \\
(14)-\end{array}$ & $\begin{array}{l}\text { (52) } 49 \% \\
(39)-\end{array}$ & $\begin{array}{l}\text { Yes } \\
\text { No }\end{array}$ \\
\hline \multicolumn{3}{|l|}{ Unselected patients: } & (118) $52 \%$ & (74) $33 \%$ & & (38) $51 \%$ & (11) $7 \cdot 3 \%$ & (18) $12 \%$ & (56) $25 \%$ & No \\
\hline $\begin{array}{l}\text { Kennedy et al } \\
(1990)\end{array}$ & 171 & 48 & - & (50) $41 \%$ & (0) $0 \%$ & (2) $4 \%$ & (6) $5 \%$ & (9) $7 \cdot 4 \%$ & (11) $6.4 \%$ & No \\
\hline Mulcahy et al & 172 & 24 & (104) $61 \%$ & (72) $42 \%$ & (2) $2 \cdot 8 \%$ & (10) $14 \%$ & (7) $7 \%$ & (15) $15 \%$ & (25) $14 \cdot 7 \%$ & No \\
\hline $\begin{array}{l}\text { Solimene et al } \\
\text { (1993) }\end{array}$ & 40 & 24 & (10) $25 \%$ & (66) $15 \%$ & (0) $0 \%$ & (0) $0 \%$ & (1) $3 \%$ & (1) $3 \%$ & (1) $2.5 \%$ & No \\
\hline $\begin{array}{c}\text { Quyyumi et al } \\
\text { (1993) }\end{array}$ & 116 & 29 & (72) $63 \%$ & (45) $39 \%$ & (1) $2 \cdot 2 \%$ & (6) $13 \%$ & (6) $8.4 \%$ & (11) $15 \cdot 5 \%$ & (17) $14.6 \%$ & No \\
\hline
\end{tabular}

-, figure not known. 


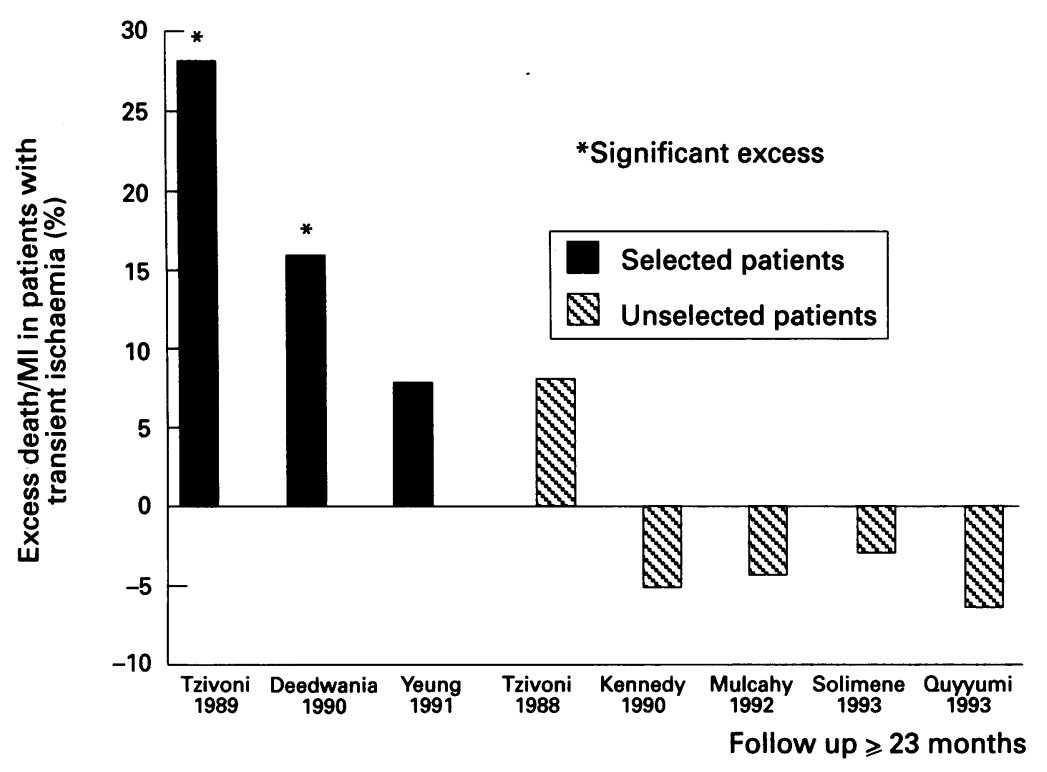

Percentage excess of cardiac death and non-fatal myocardial infarction in patients with ischaemia during daily life compared with patients without such ischaemia. Selected patients = positive exercise test was a prerequisite for inclusion. Unselected patients = positive exercise test not a prerequisite for study.

patients requiring further revascularisation had such ischaemic episodes. Kennedy et al concluded that asymptomatic ischaemia detected by ambulatory ST segment monitoring in the first year after CABG was not associated with an adverse prognosis up to four years of follow up. They also noted that such changes were not associated with increased occlusion of the bypass graft or anastomotic site.

\section{Comment}

What are we to make of these findings? Should we try to detect asymptomatic ischaemia during daily life in those with stable coronary artery disease? The accompanying figure shows the prognostic significance of ambulatory ischaemia for acute myocardial infarction/cardiac death in the reported studies. Of the eight different population groups reported on, only two showed a significantly increased risk of infarction/cardiac death in those with ischaemic episodes. Four of these eight studies did show a significantly increased frequency of all end points (including unstable angina and revascularisation) in those with ambulatory ischaemia.

Currently most physicians use information gleaned from exercise testing (or a radionuclide equivalent) together with symptoms and coronary anatomy to guide management. It is noteworthy that in the studies where an exercise test was performed but where a positive test was not a prerequisite for inclusion, ${ }^{15-18} 197$ (36\%) of 552 patients had ischaemic episodes during daily life and 304 (55\%) had a positive exercise test. Only 11 $(5 \%)$ of 197 patients with ambulatory ischaemia had a negative exercise test. Exercise testing clearly identifies those more likely to have such changes during daily activities, and seems to be considerably more sensitive in detecting ischaemia. Combining data from these studies showed that ambulatory monitoring increased the sensitivity of exercise testing for the detection of ischaemia by only $2 \%$ (from $55 \%$ to $57 \%$ ). This confirms the recent findings of Klein et al, who while suggesting that evidence of ischaemia during ambulatory monitoring was associated with a greater area of ischaemic myocardium, reported that only $33 \%$ of patients with exercise-induced ischaemia (single photon emission computed tomography with thallium) had ischaemia during ambulatory monitoring. ${ }^{20}$

It has been suggested that the documentation of ischaemia during daily life might indicate the need for more aggressive diagnostic and therapeutic approaches. The results of six of the studies we reviewed suggest that such a recommendation may be inappropriate. ${ }^{1214-161819}$ What the studies by Tzivoni et al ${ }^{12}$ and Deedwania and Carbjal ${ }^{11}$ tell us is that in highly selected patients with stable angina the additional presence of predominantly asymptomatic ischaemic episodes during daily life is an independent predictor of an adverse outcome. It could argued however, that many such patients would in any case be referred for intervention on the basis of their coronary anatomy, exercise test results, and symptoms.

The view that repeated spontaneous episodes of ischaemia are in themselves hazardous and therefore should be eradicated, is not confirmed. We still do not know whether episodes of asymptomatic or symptomatic ischaemia are simply a reflection (or marker) of significant coronary artery disease, or whether they directly lead to the end points of coronary disease. In the recent study by Quyyumi et al, where $75 \%$ of patients who had an acute cardiac event underwent repeat coronary angiography within two weeks of the event, almost all acute occlusions occurred at a site other than that of the most significant lesion at initial angiography, and where the diameter stenosis had been previously assessed as being $<50 \%$ in five of the six cases (lesions probably not sufficiently severe in themselves to cause ischaemia). ${ }^{16}$ Five of six acute infarctions reported in the study by Mulcahy et al also occurred in those without any prior objective evidence of ischaemia. ${ }^{15}$ Bearing this in mind we should not be asking "What should be done for patients with asymptomatic ischaemia?" but rather "Why do stable coronary lesions of whatever size become unstable?"

Many victims of sudden cardiac death have significant coronary disease and damaged left ventricles; none the less, the relation between ischaemic ST segment depression and sudden death remains weak. Of 75000 ambulatory electrocardiograms performed in two centres, 23 patients died suddenly during the recording period in one centre ${ }^{21}$; however, most were in hospital with acute ischaemic syndromes at the time of the event. In the other study eight patients died suddenly outside hospital. In one of them, who had rest pain, ventricular arrhythmias related to ST segment depression developed. ${ }^{22}$

We believe that it is reasonable to continue 
to refer "high risk" patients for intervention on the basis of their symptoms and the findings of coronary angiography and left ventricular function assessment, as well as exercise testing or radionuclide studies or both. Ambulatory ST segment monitoring may help to identify a high risk subgroup within such high risk patients. In most patients with stable angina with a reasonable exercise tolerance on exercise testing, however, the evidence suggests that the presence of (predominantly asymptomatic) ischaemia during daily life does not help to identify subjects at greater risk of a subsequent acute myocardial infarction or cardiac death. The case for or against investigation and intervention in such patients should remain primarily based on symptoms. The available evidence indicates that routine ambulatory ST monitoring for the detection of asymptomatic ischaemia will be of little benefit in most patients with stable angina who can exercise adequately. Nor does there appear any point in performing this investigation in the stable phase after acute myocardial infarction or coronary artery bypass surgery. We have not assessed the investigative benefits of continuous ST segment monitoring in patients with unstable angina or during the in hospital phase after acute myocardial infarction and results and conclusions reported here should not be extrapolated to these subgroups with unstable disease.

Finally all the prognostic studies in which surgery was shown to be of benefit identified particular high risk anatomical patterns (for example, left main stem disease and three vessel disease with reduced left ventricular function)..$^{23-25}$ None of these studies showed that outcome was improved primarily by the modification of ischaemic activity, whether asymptomatic or not, during daily activities. In the recent report by Yeung et al outcome in patients without ambulatory ischaemia while on treatment was no better than in patients with untreated ambulatory ischaemia, suggesting that reducing or eradicating such ischaemic episodes by medical means may not improve outcome. ${ }^{14}$ This accords with the theory that predominantly asymptomatic ischaemic episodes during daily life may be markers of significant coronary disease that may not in themselves lead to the end points of such disease.

\section{Addendum}

In a recent multicenter international study that included performing ambulatory ST segment monitoring on 936 patients who were clinically stable between 1-6 months after acute myocardial infarction or unstable angina, Moss et al reported that detection of silent or symptomatic ambulatory ischaemia was not of use in identifying patients at increased risk of subsequent coronary events over a mean 23 month follow up period. ${ }^{26}$

1 Stern S, Tzivoni D. The dynamic changes of the ST-T segment during sleep in ischemic heart disease. $A m$
Cardiol 1973;32:17-20

2 Mulcahy D, Keegan J, Crean P, et al. Silent myocardial ischaemia in chronic stable angina: a study of its frequency and characteristics in 150 patients. Br Heart $\mathcal{f}$ 1988;60:417-23.

3 Cohn PF. Silent myocardial ischemia in patients with a defective anginal warning system. Am $\%$ Cardiol 1980; 45:697-701

4 Droste C, Roskamm H. Experimental pain measurements in patients with asymptomatic myocardial ischemia. F Am Coll Cardiol 1983;1:940-5.

5 Glazier JJ, Chierchia S, Brown MJ, Maseri A. Importance of generalised defective perception of painful stimuli as a cause of silent myocardial ischaemia in chronic stable angina pectoris. Am $\mathcal{F}$ Cardiol 1986;58:667-72

6 Stern S, Gavbish A, Weisz G, Benhorin J, Keren A, Tzivoni D. Characteristics of silent and symptomatic myocardial ischaemia during daily activities. $A m \mathcal{F}$ Cardiol 1988;61:1223-8.

7 Mulcahy D, Keegan J, Fox KM. Characteristics of silent and painful ischaemia during ambulatory monitoring in patients with coronary arterial disease. Int $\mathcal{f}$ Cardiol 1990;28:377-9.

8 Deanfield JE, Selwyn AP, Chierchia S, et al. Myocardial ischaemia during daily life in patients with stable angina: its relation to symptoms and heart rate changes. Lancet 1983;i:753-8.

9 Levy RD, Shapiro LM, Wright C, Mockus L, Fox KM. The haemodynamic significance of asymptomatic ST segment depression assessed by ambulatory pulmonary segment depression assessed by ambulatory pulmonary

10 Rocco MB, Nabel EG, Campbell S, et al. Prognostic importance of myocardial ischaemia detected by ambulatory monitoring in patients with stable coronary artery disease. Circulation 1988;78:877-84.

11 Deedwania PC, Carbajal EV. Silent ischemia during daily life is an independent predictor of mortality in stable life is an independent predictor of

12 Tzivoni D, Weisz G, Gavish A, Zin D, Keren A, Stern S. Comparison of mortality and myocardial infarction rates in stable angina pectoris with and without ischemic episodes during daily activities. Am f Cardiol 1989;63: 273-6.

13 Brunelli C, Cristofani R, L'Abbate A. Long-term survival in medically treated patients with ischaemic heart disease and prognostic importance of clinical and electrocardiographic data. Eur Heart f 1989;10:292-303.

14 Yeung AC, Barry J, Orav J, Bonassin E, Raby KE, Selwyn AP. Effects of asymptomatic ischemia on long-term prognosis in chronic stable coronary disease. Circulation 1991;83:1598-604.

15 Mulcahy D, Parameshwar J, Holdright D, et al. Value of ambulatory ST segment monitoring in patients with chronic stable angina: Does measurement of the "total ischaemic burden" assist with management? Br Heart $\mathcal{f}$ 1992;67:47-52.

16 Quyyumi AA, Panza JA, Diodati JG, Callahan TS, Bonow RO, Epstein SE. Prognostic implications of myocardial ischemia during daily life in low risk patients with coronary artery disease. $\mathcal{F} \mathrm{Am}$ Coll Cardiol 1993;21:700-8.

17 Tzivoni D, Gavish A, Zin D, et al. Prognostic significance of ischemic episodes in patients with previous myocarof ischemic episodes in patients with previo
dial infarction. Am $\mathcal{\text { Cardiol }} 1988 ; 62: 661-4$.

18 Solimene MC, Ramires JAF, Gruppi CJ, et al. Prognostic significance of silent myocardial ischaemic after a first significance of silent myocardial ischaemic after a first uncomplicated

19 Kennedy HL, Seiler SM, Sprague MK, et al. Relation of silent myocardial ischemia after coronary artery bypass grafting to angiographic completeness of revascularization and long-term prognosis. Am $\mathcal{F}$ Cardiol 1990;65: $14-22$

20 Klein J, Rodrigues EA, Berman DS, Prigent F, Chao SY, Maryon T, Rozanski A. Prevalence and functional significance of transient ST-segment depression during daily life activity: Comparisons of ambulatory ECG with stress redistribution thallium-201 single-photon emission computer tomographic imaging. Am Heart $f$ 1993; 125:1247-57.

21 Savage HR, Kissane JQ, Becher EL, et al. Analysis of ambulatory electrocardiograms in 14 patients who expeCardiol 1987;10:621-32.

22 Dubner SJ, Pinski S, Palma S, et al. Ambulatory electrocardiographic findings in out-of-hospital cardiac arrest secondary to coronary artery disease. Am $\mathcal{F}$ Cardiol 1989;14:1618-25.

23 The Veterans Administration Coronary Artery Bypass Surgery Cooperative Study Group. Eleven year survival in the Veterans Administration randomized trial of coronary bypass surgery for stable angina. $N$ Engl $f$ Med nary bypass surge

24 Varnauskas E and the European Coronary Surgery Study Group. Twelve year follow-up of survival in the randomized European Coronary Surgery Study. $N$ Engl $\mathcal{f}$ Med 1988;319:332-7.

25 Alderman EL, Bourassa MG, Cohen LS, et al. Ten-year follow-up of survival and myocardial infarction in the follow-up of survival and myocardial infarction in the randomized Coro

26 Moss AJ, Goldstein RE, Hall J, et al. Detection and significance of myocardial ischemia in stable patients after recovery from an acute coronary event. $f \mathrm{Am} \mathrm{Med} \mathrm{Assoc}$ 1993;269:2379-85. 